\title{
A Case of Mucocele Occurred in Nasal Septum
}

\author{
Soo-Ah Hong, Top Kim, Hee Won Wu, and Hyun Jun Kim \\ Department of Otolaryngology, Ajou University School of Medicine, Suwon, Korea
}

\section{비중격에 발생한 점액낭종 1 예}

홍수아 · 김 탑 · 우희원 · 김현준

아주대학교 의과대학 이비인후과학교실

\author{
Received October 27, 2015 \\ Revised November 4, 2015 \\ Accepted November 4, 2015 \\ Address for correspondence \\ Hyun Jun Kim, MD, PhD \\ Department of Otolaryngology, \\ Ajou University School of Medicine, \\ 164 World cup-ro, Yeongtong-gu, \\ Suwon 16499, Korea \\ Tel $+82-31-352-5636$ \\ Fax $+82-31-219-5264$ \\ E-mail entkhj@ajou.ac.kr
}

\begin{abstract}
Mucoceles are expansile, encapsulated, benign cystic lesions with the potential for adjacent bony remodeling and resorption. Paranasal mucoceles predominantly develop in the frontal sinuses $(60 \%)$, followed in frequency by the ethmoidal (20-30\%), maxillary $(10 \%)$, and sphenoid $(2-3 \%)$ sinuses. Nasal septal mucoceles develop in only very seldom cases. Septal mucoceles might develop from infected nasal septum or trauma. In the differential diagnosis of a midline septal mass, dermoid cyst, encephalocele, meningocele or intraseptal abscess should be considered. We present a case of nasal septal mucocele, which was managed by endoscopic excision and marsupialization. Korean J Otorhinolaryngol-Head Neck Surg 2016;59(2):170-3
\end{abstract}

Key Words Endoscopic surgery $\cdot$ Mucocele $\cdot$ Nasal obstruction $\cdot$ Nasal septum.

\section{서 론}

비과 영역에서의 점액낭종은 부비동의 점막에 의하여 경계 가 지워지는 공간 내에 점액이 저류되는 확장성 낭종성 병변 이다. ${ }^{1,2)}$ 점액낭종은 전두동, 사골동에서 주로 발생하는 것으 로 보고되고 있으며, 비중격에 발생하는 점액낭종은 매우 드 문 것으로 알려져 있다. ${ }^{1-4)}$ 저자들은 비폐색을 유발한 비중격 내 점액낭종을 내시경적 절제술 및 조대술을 시행하여 치료한 1 예를 경험하여 이를 문헌고찰과 함께 보고하는 바이다.

\section{증 례}

52세 남자 환자가 수년간 지속되는 양측 비폐색을 주소로 내원하였다. 환자는 17세에 코 수상하였던 외상력 외에 특이 과거력 없었으며, 계통적 문진상 지속적인 비폐색 이외에 특이 증상은 없었다. 이학적 검사상 전방 비중격의 중앙부가 팽창되 어 있었고 좌측으로 편위되어 있었으며, 점액농성 비루나 출혈 혹은 비강 내 종물은 관찰되지 않았다(Fig. 1). Osteomeatal unit computed tomography(OMU CT)상 전방 비중격 내 달
걀껍질 모양의 골 변형을 동반한 종물 및 좌측으로 비중격 편 위가 관찰되었으며, 종물 내부는 연조직과 비슷한 정도의 균 등한 음영을 보이고 있었고, paranasal sinus magnetic resonance imaging의 T1 강조영상에서 저신호, T2 강조영상에서 고신호로 나타났으며, 격막이나 고형성분이 없는 약 $2.3 \mathrm{~cm}$ 크기의 둥근 모양의 균질한 음영을 나타내었다(Fig. 2). 비중 격 농양여부를 감별하기 위하여 외래에서 세침 흡인 세포검사 시행하였다. 흡인액은 투명한 적갈색의 점액성의 액체였으며, 세포도말검사상 다량의 조직구가 있는 것으로 나타났으나, 악 성 세포는 발견되지 않아 점액낭종 가능성이 클 것으로 판단 하였다. 비폐색 증상 호전 및 조직학적 확진을 위해 내시경 수 술을 계획하였다.

내시경 하에서 양측 비중격 팽창 부위를 확인한 후 좌측 비 강으로 반관통절개를 시행하였다. 비중격 연골 위로 연골막을 따라 박리를 시행하였으며, 절개부위의 $1 \mathrm{~cm}$ 거리에서 종물 의 외막을 확인할 수 있었다. 외막을 절개하자 약 $4 \mathrm{cc}$ 의 적갈 색의 점액성 액체가 배출되었으며, 종물의 외막을 비중격 점 막과 박리하여 제거하고 배액로를 형성하는 조대술을 시행하 였다(Fig. 3). 
수술 후 안구 주변 반상출혈이나 전비강 출혈, 후비 출혈은 보이지 않았으며, 안구운동 장애나 복시를 호소하지 않았고, 수술 후 2일째에 합병증 없이 퇴원하였다. 조직 검사상 만성
염증 및 내부의 출혈, 섬유화를 동반한 호흡기 상피 조직 소견 이 관찰되어 점액낭종으로 최종 진단되었다(Fig. 4).

외래 경과 관찰 중 환자의 주관적 코막힘 증상은 호전되고
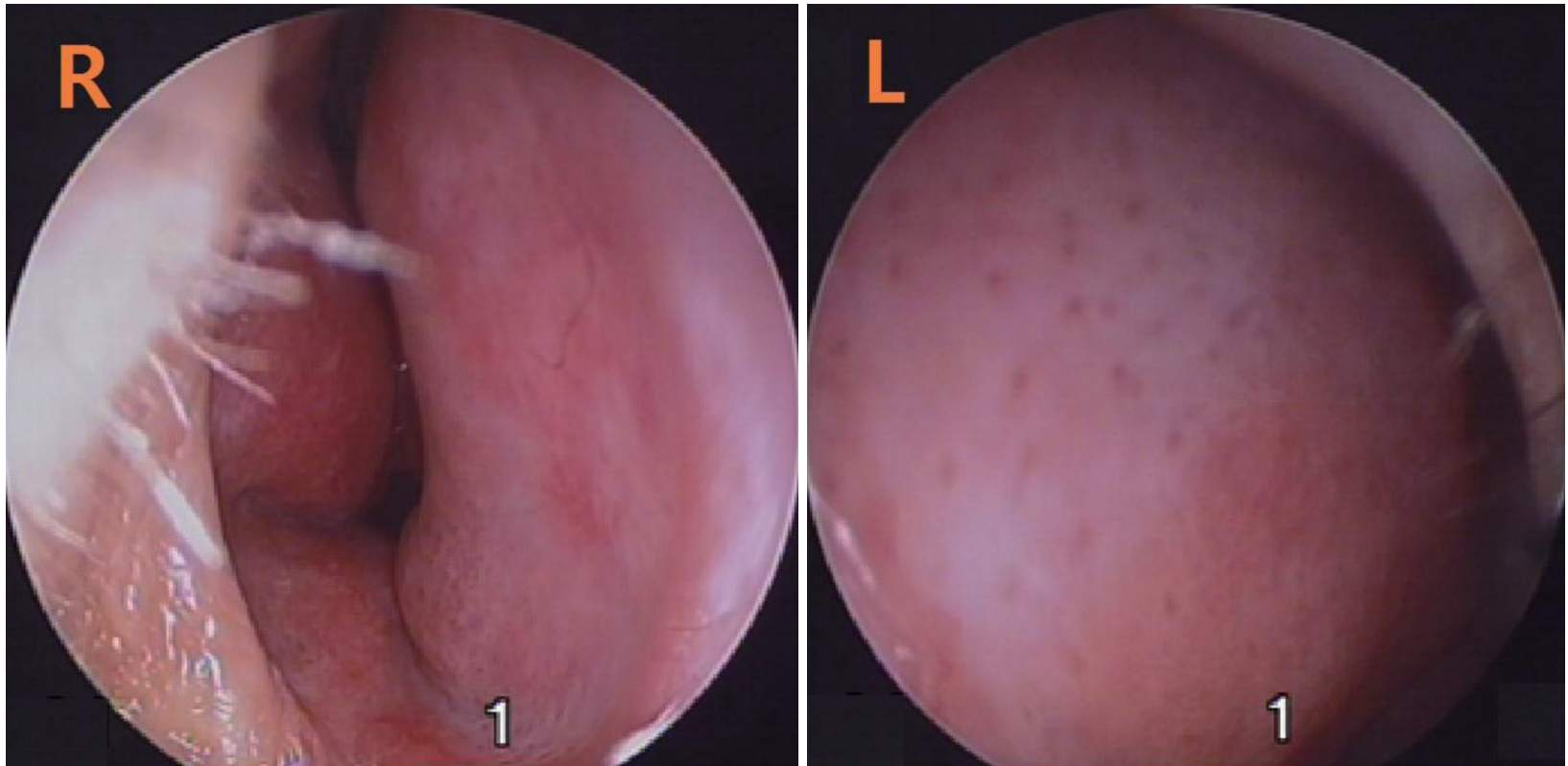

Fig. 1. In preoperative endoscopic findings, bilateral nasal septum were swollen. Nasal septum was deviated to left side.
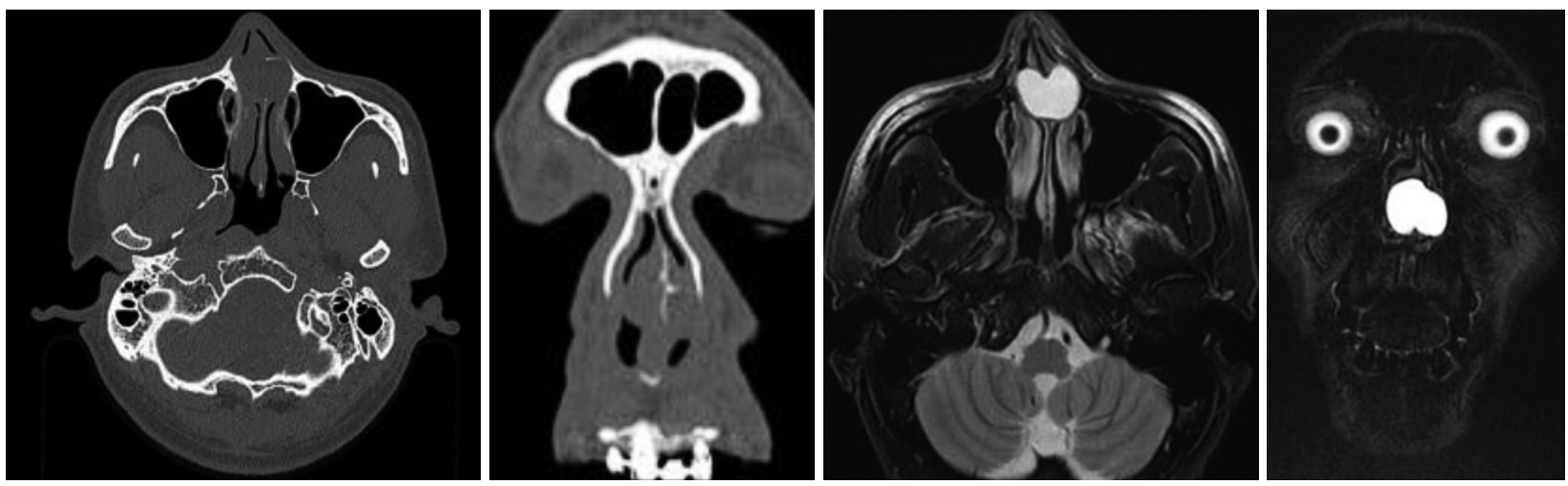

Fig. 2. Preoperative osteomeatal unit CT and T2-weighted MRI show a homogenous cystic mass located at the anterior portion of the nasal septum. Mass was about $2.3 \mathrm{~cm}$ sized well demarcated cystic mass without septation or solid portion.
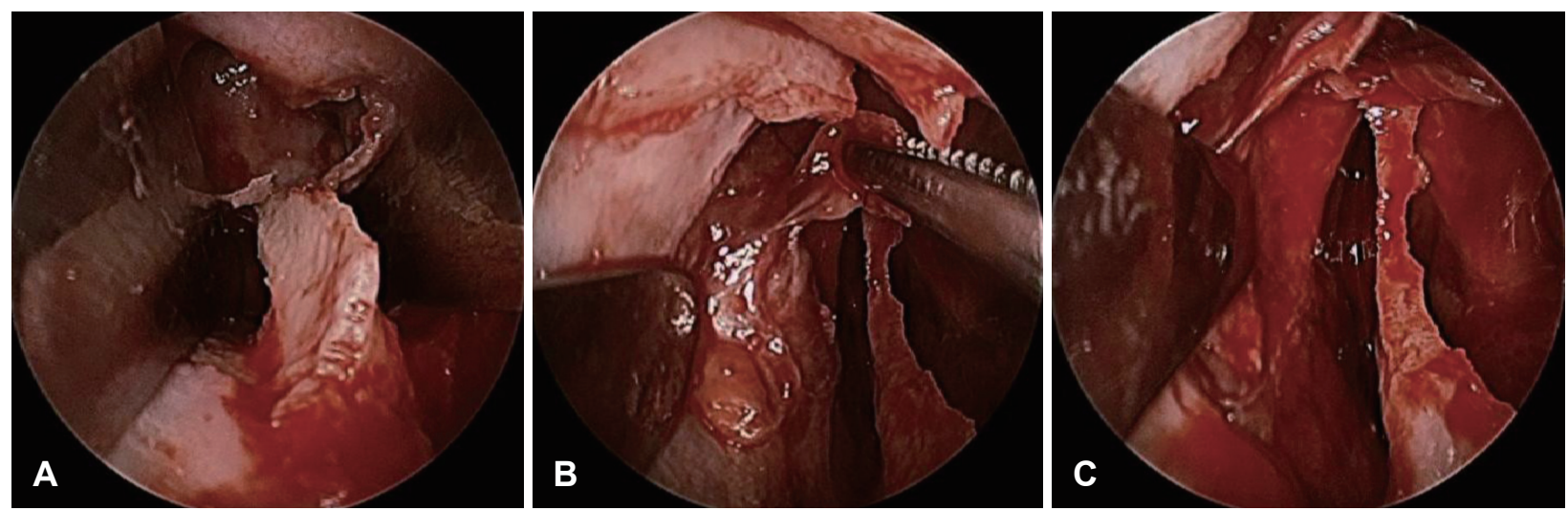

Fig. 3. Intraoperative endoscopic finding. After contents of mucocele was evacuated, mucocele's lining was identified in nasal septum (A). Mucocele's lining was dissected and removed (B). After mucocele excision, marsupialization was done through nasal septum (C). 
비중격천공 등의 술 후 합병증은 없었으며, 술 후 3 개월째 시 행한 전산화단층촬영 상 비중격 만곡은 개선되었으며, 잔여 점액낭종 및 재발 소견은 관찰되지 않았다(Fig. 5).

\section{고 찰}

점액낭종은 상피와 골이 상호작용하는 동적인 과정을 통해 동 내에 점액이 갇힌 상태로 채워져 분리되어 형성된다. ${ }^{5)}$ 이는 일반적으로 부비동의 수술 후 상처 치유 과정에서 발생되는 개구부의 폐쇄에서 기인하거나, 만성 염증, 외상, 양성 종양 등 이 선행됨으로써 일어나는 것으로 알려져 있다. ${ }^{6-9)}$ 비중격에서 발생하는 점액낭종은 2002년 Gall과 Witterick ${ }^{10)}$ 에 의해 처음

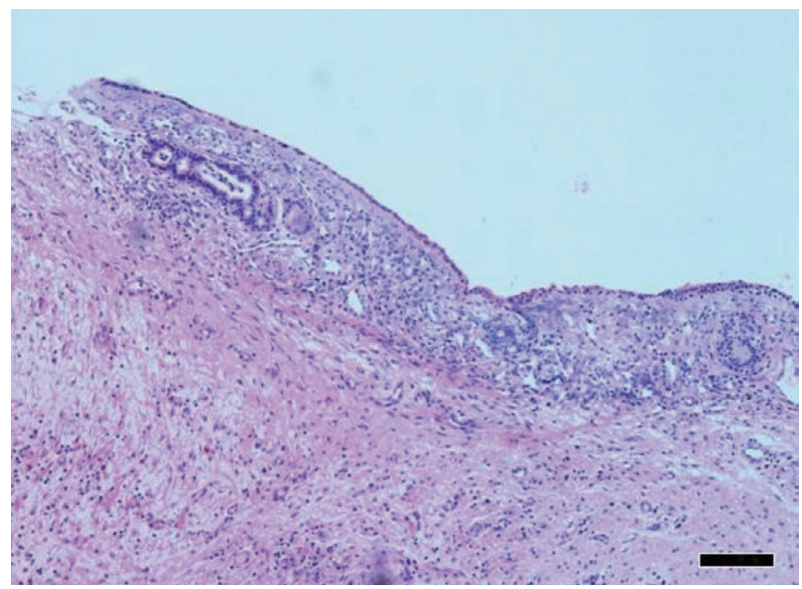

Fig. 4. Histopathology of the cyst walls (H\&E stain; scale bar=100 $\mu \mathrm{m})$. The wall of the cysts are lined with respiratory epithelium.

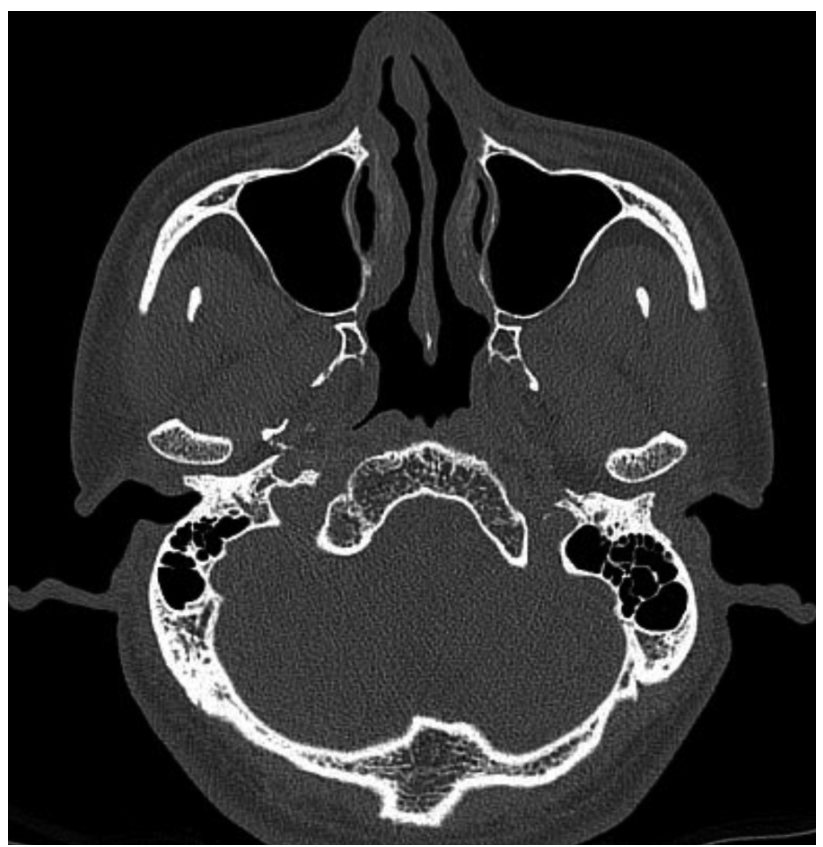

보고된 이후로 굉장히 드물게 보고되고 있다.

점액낭종 발생 시 증상은 해당부위의 팽창과 주위 조직의 압박에 의해 나타나며 두통, 안구돌출 혹은 시력장애, 비폐색 등이 있다. ${ }^{11)}$ 비중격 내 점액낭종 발생시에는 비폐색이 주증상 이며 비통증, 두통이 동반되는 것으로 보고되었다. ${ }^{1-4)}$ 임상증 상은 점액낭종 형성되는 초기에는 발견되기 어려우며 증상이 발현되기까지는 1 2년의 기간이 경과되는 경우가 많은 것으 로 알려져 있으며, 특히 점액낭종이 외상 후 이차적으로 발생 되는 경우 늦게 발견되는 경우가 많으며 평균 7.5년이라고 보 고되었으며, ${ }^{11,12)}$ 여러 증례에서는 외상 후 1 50년 후에 발견되 는 등 다양하게 보고되었다. ${ }^{13,14)}$ 본 증례의 환자도 비부 외상 35년 후 점액낭종이 발견되었으며, 안면부 및 비부 외상 이후 에는 오랜 기간의 경과 관찰이 필요할 수 있다. ${ }^{3)}$

점액낭종의 이학적 소견은 주로 해당부위의 팽창성 병변으 로 관찰되며, 비중격 점액낭종 증례들에서는 양측이 팽창된 비중격이 공통적으로 확인되며 비중격 편위가 나타나는 경우 도 있었다. ${ }^{1-4)}$ 점액낭종은 증상 및 이학적 소견만으로는 정확한 진단이 어려워 영상 검사가 필수적으로, CT를 통하여 골미란 여부를 관찰할 수 있고, 이전의 외상이나 수술 등에 의해 왜 곡된 구조를 알 수 있어 점액낭종에서 최선의 진단 방법으로 생각된다. 또한 $\mathrm{CT}$ 는 악성 및 양성종양이나 진균성 질환을 감 별하는 데 유용하게 사용될 수 있다.8) 비중격 내 점액낭종은 영상의학적 검사에서 비중격 내부에 둥근 형태의 종물로 보이 며, 종물 내부의 음영이 균질한 양상으로 나타난다. 이 부위에 발생하는 종물은 유피낭포, 뇌류, 점액낭종 등의 양성 종양 및

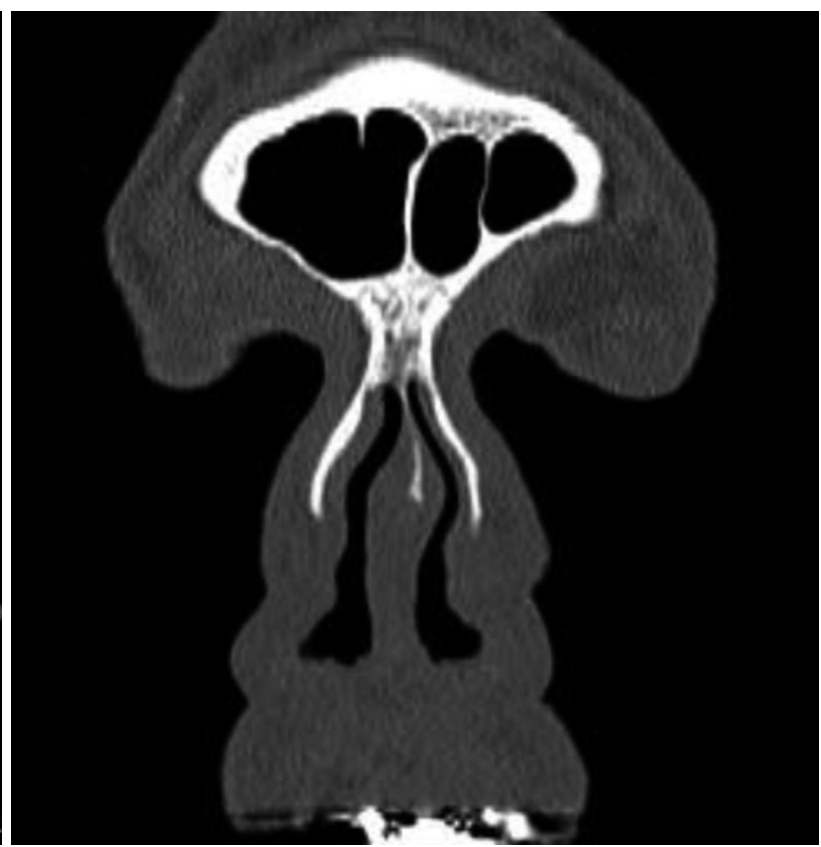

Fig. 5. Osteomeatal unit CT at postoperative 1 year. Follow-up is in place to continue surveillance for recurrent or additional mucocele formation. 
감염에 의한 농양 등에 대한 감별진단이 필요하다. ${ }^{1)}$

점액낭종에 대한 수술적 접근법은 위치에 따라 두개내 접 근이나 견치와를 통한 접근, 경측두골법 등 비 외 접근도 가 능하나 최근에는 내시경의 발달에 따라 비 내 내시경 접근법 이 주를 이루고 있다. 이 방법은 국소마취 하에도 시행이 가능 하며 수술 조작이 용이하며 직시(direct vision) 하에서 명확 한 구조를 파악하며 시술할 수 있어 출혈이 적고, 합병률(2\%) 및 이환율과 재원기간이 적다는 장점이 있다. ${ }^{6,11,15)}$

점액낭종의 수술적 치료 방법은 크게 나누어 침범된 부비 동의 전부와 점액낭종을 광범위하게 제거하거나, 점막을 그대 로 두고 내시경적 조대술을 통해 배액시키는 방법이 있다. 본 증례에서는 비 내 내시경 접근을 통해 비중격 내의 점액 흡인

및 조대술을 시행하였고, 낭종막을 제거하였다.

비중격 내 점액낭종은 발생빈도가 낮아 매우 드물게 보고 되고 있으며, 국내에는 보고된 적이 없다., ${ }^{1,3,40)}$ 저자들은 비중 격 내 점액낭종을 비내시경 하 절제술 및 조대술로 성공적으 로 치료하였기에 문헌고찰과 함께 보고하는 바이다.

\section{REFERENCES}

1) Yilmaz MS, Guven M, Dicle M. Nasal septal mucocele in a child: a rare presentation. Int J Pediatr Otorhinolaryngol Extra 2011;6(4): 414-5.

2) Canalis RF, Zajtchuk JT, Jenkins HA. Ethmoidal mucoceles. Arch Otolaryngol 1978;104(5):286-91.

3) Cannon DE, Wells TS, Poetker DM. Two late complications of craniofacial trauma: case report and review of the literature. Am J Otolaryngol 2012;33(5):615-8.

4) Taskin U, Korkut YA, Aydin S, Oktay FM. Atypical presentation of primary giant nasal septal mucopyocele. J Craniofac Surg 2012; 23(1):e5-7.

5) Hartley BE, Lund VJ. Endoscopic drainage of pediatric paranasal sinus mucoceles. Int J Pediatr Otorhinolaryngol 1999;50(2):109-11.

6) Jeon EJ, Park JY, Yoo HJ, Kim DH. A case of isolated abducens nerve palsy caused by primary sphenoid sinus mucocele. Korean J Otorhinolaryngol-Head Neck Surg 2010;53(12):781-3.

7) Chui MC, Briant TD, Gray T, Horsey WJ, Hudson AR, Tucker W. Computed tomography of sphenoid sinus mucocele. J Otolaryngol 1983;12(4):263-9.

8) Kösling S, Hintner M, Brandt S, Schulz T, Bloching M. Mucoceles of the sphenoid sinus. Eur J Radiol 2004;51(1):1-5.

9) Chung JS, Yoo YW, Seo JY, Choi HS, Kang SH. A case of sphenoid sinus mucocele. Korean J Otolaryngol-Head Neck Surg 1997;40(12): 1848-52.

10) Gall R, Witterick I. Mucocele of the nasal septum. J Otolaryngol 2002;31(4):246-7.

11) Lee KC, Kwon KH, Kang HG, Jin SM, Lee YB. Endoscopic sinus surgery in paranasal sinus mucoceles. Korean J Otolaryngol-Head Neck Surg 1997;40(6):855-60.

12) Smoot EC 3rd, Bowen DG, Lappert P, Ruiz JA. Delayed development of an ectopic frontal sinus mucocele after pediatric cranial trauma. J Craniofac Surg 1995;6(4):327-31.

13) Koudstaal MJ, van der Wal KG, Bijvoet HW, Vincent AJ, Poublon RM. Post-trauma mucocele formation in the frontal sinus; a rationale of follow-up. Int J Oral Maxillofac Surg 2004;33(8):751-4.

14) Mourouzis C, Evans BT, Shenouda E. Late presentation of a mucocele of the frontal sinus: 50 years postinjury. J Oral Maxillofac Surg 2008;66(7):1510-3.

15) Stankiewicz JA. Sphenoid sinus mucocele. Arch Otolaryngol Head Neck Surg 1989;115(6):735-40 